
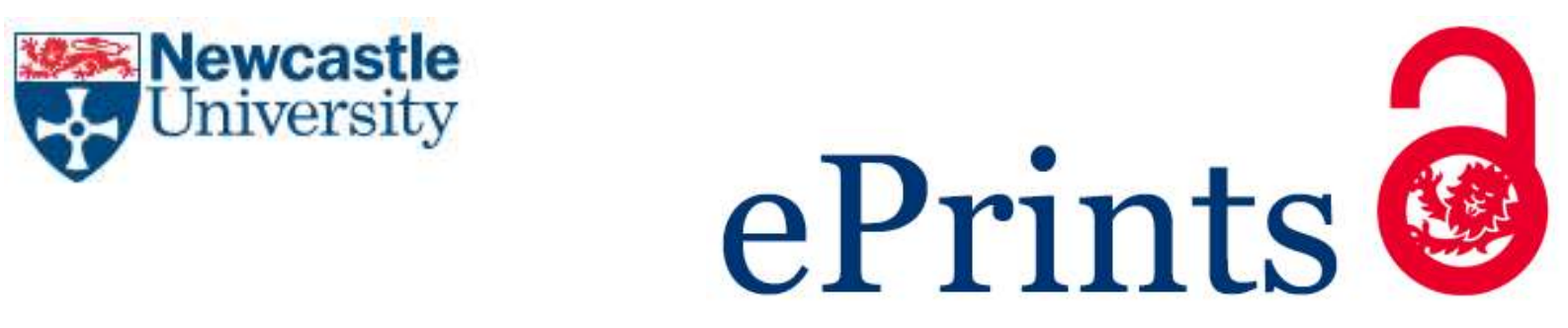

Sauer C, Syvertsson S, Bohorquez LC, Cruz R, Harwood CR, van Rij T, Hamoen LW. Effect of Genome Position on Heterologous Gene Expression in Bacillus subtilis: An Unbiased Analysis. ACS Synthetic Biology 2016

DOI: http://dx.doi.org/10.1021/acssynbio.6b00065

\title{
Copyright:
}

The final publication is available at ACS Publications via http://dx.doi.org/10.1021/acssynbio.6b00065

Date deposited:

$18 / 07 / 2016$

Embargo release date:

20 May 2017

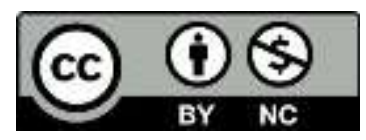

This work is licensed under a Creative Commons Attribution-NonCommercial 3.0 Unported License 


\section{Effect of genome position on heterologous gene expression in Bacillus subtilis; an unbiased analysis}

Christopher Sauer ${ }^{1,2,4}$, Simon Syvertsson ${ }^{1,4}$, Laura C. Bohorquez ${ }^{3}$, Rita Cruz ${ }^{1,2}$, Colin R. Harwood ${ }^{1}$, Tjeerd van Rij ${ }^{2}$, Leendert W. Hamoen ${ }^{1,3,5}$

${ }^{1}$ Centre for Bacterial Cell Biology, Institute for Cell and Molecular Biosciences, Newcastle University, Richardson Road, NE2 4AX Newcastle, United Kingdom

${ }^{2}$ DSM Biotechnology Center, P.O. Box 1, 2600 MA Delft, The Netherlands

${ }^{3}$ Bacterial Cell Biology, Swammerdam Institute for Life Sciences, University of Amsterdam, De Boelelaan, $1081 \mathrm{HZ}$ Amsterdam, The Netherlands

${ }^{4}$ Both authors contributed equally

${ }^{5}$ Corresponding author: Leendert W. Hamoen, University of Amsterdam, I.w.hamoen@uva.nl

Keywords: Bacillus subtilis, gene expression, genome location, transposon, GFP, LacZ 


\section{ABSTRACT}

A fixed gene copy number is important for the in silico construction of engineered synthetic networks. However, the copy number of integrated genes depends on their genomic location. This gene dosage effect is rarely addressed in synthetic biology. Two studies in Escherichia coli presented conflicting data on the impact of gene dosage. Here, we investigate how genome location and gene orientation influences expression in Bacillus subtilis. An important difference with the $E$. coli studies is that we used an unbiased genome integration approach mediated by random transposon insertion. We found that there is a strong gene dosage effect in fast growing B. subtilis cells, which can amount to a 5-fold difference in gene expression. In contrast, gene orientation with respect to DNA replication direction does not influence gene expression. Our study shows that gene dosage should be taken into account when designing synthetic circuits in $B$. subtilis and presumably other bacteria.

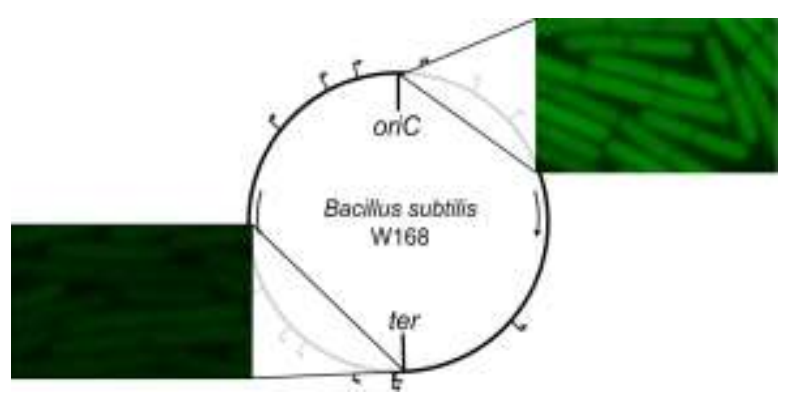




\section{INTRODUCTION}

Bacillus subtilis is widely used as bacterial model system and for the production of enzymes and vitamins. It is genetically tractable, easily culturable and regarded as safe. This has resulted in the development of a wide array of genetic tools for use in both academic and industrial environments, and has made the organism a popular cloning chassis in synthetic biology. ${ }^{1}$ The natural genetic transformation system of $B$. subtilis facilitates the integration of DNA into the genome by homologous recombination. ${ }^{2,3}$ In contrast to the use of plasmids as genetic carriers, genome integration assures that heterologous genetic material is stably maintained at a copy number that reflects that of the chromosome. The latter is important when genetic modules (e.g. biobricks) are used for the construction of engineered synthetic metabolic pathways and regulatory networks. ${ }^{1,4}$ However, since DNA replication originates at a fixed position on the genome (origin of replication), and rapidly growing bacteria initiate new rounds of replication before the previous rounds have been completed, the copy number of integrated genes will fluctuate. As a result, gene dosage rises with increasing proximity to the origin of replication. ${ }^{5,6}$ Another aspect that might affect the activity of integrated genes is the transcriptional orientation. The majority of native genes are co-directional with DNA replication ${ }^{7-9}$ in order to reduce collisions between RNA polymerase and the DNA replication machinery. ${ }^{10,}{ }^{11}$ It is therefore possible that the orientation of integrated genes will influence expression. In this study, we set out to determine to which extent genome location and gene orientation influences heterologous gene expression in B. subtilis.

Several groups have studied the effects of genome location on gene expression using the model organism Escherichia coli. By varying the position of a reporter gene on the genome, Block and coworkers have shown that expression is only influenced by gene dosage and not by the orientation of the gene relative to the direction of DNA replication. ${ }^{12}$ They found that in rapidly growing cultures of $E$. coli the maximum expression levels were approximately 9-fold higher for gene locations close to the origin of replication compared to locations close to the replication terminus. ${ }^{12}$ More recently, Bryant and coworkers reported that gene expression can vary up to 300 -fold for a reporter fusion that was integrated at different locations on the E. coli genome. ${ }^{13}$ Moreover, they concluded that gene dosage 
had only a minor influence on expression, and that the observed differences are related to specific features involved in chromosome organization. The discrepancy between these reports may therefore reflect the particular locations chosen for the integration of the reporter fusions. ${ }^{12,}{ }^{13}$ To prevent this complication, we developed an unbiased reporter integration approach for $B$. subtilis.

Instead of choosing the insertion sites of reporter genes, we used a transposon-mediated random insertion approach and selected clones exhibiting a wide range of expression activities. Following this approach, we found that expression of a lacZ reporter gene can differ up to 5-fold based on its chromosomal location. This difference in expression correlated strongly with the location of the reporter cassette relative to the origin of replication, and was not influenced by gene orientation with respect to the DNA replication direction. Thus, gene dose is an important factor influencing heterologous gene expression in $B$. subtilis, and this should be taken into account when designing in silico synthetic regulatory circuits, and also when expressing commercially valuable heterologous proteins. 


\section{RESULTS \& DISCUSSION}

\section{Unbiased chromosome insertion}

To be able to make an unbiased assessment of the influence of genomic location on gene expression in $B$. subtilis, we made use of the Mariner transposon. ${ }^{14,}{ }^{15}$ This transposon only requires a TA dinucleotide sequence for transposition and consequently it is known to insert randomly into the genome. ${ }^{16-18}$ To determine the influence of gene orientation on expression, a bidirectional reporter cassette was constructed comprising the constitutively active $\mathrm{P}_{\text {veg }}$ promoter and the inducible $\mathrm{P}_{\text {spac }}$ promoter, fused, respectively to gfp and lacZ reporter genes (Figure 1). To control the $\mathrm{P}_{\text {spac }}$ promoter, the lacl repressor gene was integrated into the genome at the aprE locus. Transcriptional read-through from and into adjacent genes was avoided by the inclusion of strong bidirectional terminators at both ends of the cassette (Figure 1). These bidirectional B. subtilis terminators were identified using the WebGeSTer database. ${ }^{19}$ The reporter cassette was subsequently cloned into the Mariner transposon. Despite the size of the cassette $(\sim 6 \mathrm{~kb})$, the transposon was still active, albeit with a transposition frequency that was an order of magnitude lower than the wild type transposon (Supporting Information Table S1).

Following transposition, cells were grown on nutrient agar plates containing X-gal and IPTG, and colonies showing a range of color intensities, from dark blue to almost white, were selected at random for detailed analysis. To ensure that the transposon insertions did not influence growth, the growth rates of the selected clones were measured in microtiter plates. Fourteen clones that showed normal growth rates (Supporting Information Figure S1) were selected for further analyses. The locations of the transposon insertions on the $B$. subtilis genome are shown in Figure 2 and detailed genetic information about these loci is provided in the Supporting Information (Figure S2).

\section{Effect of genome position}

The fourteen transposon insertion strains were grown in LB medium at $37^{\circ} \mathrm{C}$ in the presence of $1 \mathrm{mM}$ IPTG, and samples were taken during exponential growth $\left(\mathrm{OD}_{600} \sim 0.5\right)$ to determine $\beta$-galactosidase activity and fluorescence intensity (GFP) measurements. Figure $3 A$ shows the $\beta$-galactosidase activity 
and GFP fluorescence intensity with respect to the locations of the transposons on the genome. The orientation of the reporter genes is indicated by arrowheads. The trend lines show a clear correlation between chromosome location and gene expression for both reporters. The maximum difference in expression between a gene located close to the replication origin (oriC) or to the terminus (ter) is approximately 5-fold. The differences in GFP expression levels are clearly visible by eye (Figure 3B). The experiment was carried out in triplicate and a representative set of data is shown in the Supporting Information (Figure S3A).

To determine whether the observed activities were influenced by read-through from adjacent genes, $\beta$-galactosidase activities were also measured in the absence of IPTG. In the eight transposon clones tested, the absence of IPTG resulted in very low $\beta$-galactosidase activities, maximally of 6 Miller Units (Supporting Information Figure S4), indicating that the reporter cassette is transcriptionally isolated by the flanking bidirectional terminators, and therefore not influenced by transcriptional readthrough from adjacent genes.

It has been reported that in $B$. subtilis the copy number of a gene close to oriC can be $\sim 5$ times higher than that of a gene close to the ter (ori:ter ratio) when growing exponentially ( 2.5 doublings/h) in LB medium. ${ }^{20}$ To examine the relation between expression and gene dosage, DNA copy numbers of the different loci were determined using qPCR (Figure 3C). We found a comparable ori:ter ratio as described before,${ }^{20}$ and a distribution of DNA copy numbers of the different loci that reflects the trends of lacZ and gfp expression, indicating that gene dosage is a major factor influencing gene expression in fast growing cells.

\section{Outliers}

Despite the clear relationship between expression levels and the genomic location of the reporters, a few transposon insertions deviated from the trend lines (see arrows Figure 3A). For example, the transposon integrated close to oriC $\left(\sim 1^{\circ}\right)$ showed a much lower $\beta$-galactosidase activity than expected, even though the sequences of the lacZ gene and $P_{s p a c}$ promoter did not reveal any mutations. This transposon was inserted into the non-essential ribosomal gene $r r n O-23 S$ that is part of the $r r n O-16 S$ operon (Supporting Information Figure S2). Possibly, the terminator of the transposon cassette is not 
fully able to prevent read-through from the strongly transcribed $\mathrm{rnO}-16 \mathrm{~S}$ operon. The transposon insertion at $332^{\circ}(s p s C)$ showed a significantly lower than expected GFP activity for reasons that are currently unknown (Figure 3A).

\section{Effect of transcription direction}

Like most other bacteria, the orientation of genes on the $B$. subtilis genome is strongly correlated with the direction of DNA replication. ${ }^{7,9}$ To determine whether gene orientation affected expression, $\beta$ galactosidase activities and GFP fluorescence intensities were analyzed with respect to their orientation, as indicated in Figure 4. The expression levels were plotted against the distance of the transposon insertion sites from the origin of replication. The outliers at $1^{\circ}$ and $332^{\circ}$ were discarded in this analysis. The resulting trend lines are comparable (Figure 4), indicating that gene orientation did not have a strong influence on expression levels. One replicate is shown in Supporting Information Figure S3B-C. At first sight this might seem surprising considering the strongly biased orientation of the genes on the genome, however, this bias is likely related to the negative effect of RNA polymerases colliding with the DNA replication machinery, resulting in less efficient DNA replication rather than effecting transcription efficiency.

\section{Effect of growth rate reduction}

B. subtilis grows considerably slower in minimal medium containing glucose and amino acids than in nutritionally rich LB medium. ${ }^{21,22}$ This is also reflected in a lower ori:ter ratio which in minimal medium approaches $3: 1 .^{20}$ If expression differences are indeed due to gene dosage effects, this should be reflected in a reduced expression ratio when grown in minimal medium. To test this, four transposon strains were selected; two with the reporter cassette close to the terminus $\left(181^{\circ}\right.$ and $\left.191^{\circ}\right)$ and two with the reporter cassette close to the origin of replication $\left(5^{\circ}\right.$ and $\left.342^{\circ}\right)$. The strains were grown in LB medium and minimal medium with mean generation times at $37^{\circ} \mathrm{C}$ of 27 min and 45 min, respectively. Indeed, growth in minimal medium reduced the difference in lacZ expression from around 3.5-fold to 2.5-fold compared to LB (Figure 5). However, the gfp marker, for unknown reasons, did not show a clear reduction in expression. 
Murray and Koh have shown that the ori:ter ratio is similar when B. subtilis is grown in LB medium at $30^{\circ} \mathrm{C}$ and $37^{\circ} \mathrm{C},{ }^{20}$ despite the mean generation time at $30^{\circ} \mathrm{C}$ (50 min) being virtually double that at $37^{\circ} \mathrm{C}(27 \mathrm{~min})$. This appears to be reflected in the unchanged expression activities of both marker genes (Figure 5).

\section{Expression differences in stationary phase}

Since DNA replication is markedly reduced when exponential growth ceases, the differential expression of different transposon strains should decrease as well. However, when we measured $\beta$-galactosidase activities and GFP intensities during stationary phase, the differential expression profiles with respect to location were still observed (Figure 6A \& B. Replicate shown in Figure S5). Both $\beta$-galactosidase and GFP are stable proteins and a possible explanation might be that the observed trends are still visible in the stationary growth phase as a consequence of the difference in reporter protein expression during logarithmic growth. To test this, lacZ was induced only in the stationary phase (Figure 6A) and, as expected, the observed $\beta$-galactosidase levels were much smaller compared to the induction of lacZ during logarithmic growth (compare Y-axis scales). More importantly, the difference in lacZ expression between the transposon strains was almost completely abolished (Figure 6C). To confirm that this effect is a consequence of a reduction in gene dosage, the DNA copy numbers of the different loci were determined using qPCR (Figure 6D). Again the distribution of DNA copy numbers followed closely the trend observed for lacZ expression.

\section{Conclusion}

Our unbiased selection approach shows that gene dosage as a consequence of multiple replication forks plays a considerable role in gene expression in $B$. subtilis, which is in full agreement with the study of Block and coworkers, ${ }^{12}$ but does not support the conclusions from the study by Bryant and coworkers. ${ }^{13}$ Similar to Block and coworkers, we also found that the orientation of reporter genes has no influence on expression levels. The importance of gene dosage in $B$. subtilis is not restricted to heterologous proteins as was shown in two recent studies that revealed the impact of chromosomal location of genes involved in the regulation of motility, biofilm development and sporulation. ${ }^{23,24}$ 
Clearly, gene dosage effects have to be taken into account when locating synthetic circuits in bacteria. Moreover, a potential 5-fold increase in enzyme production represents a commercially significant improvement. In fact, our transposon reporter system might be adapted to improve the production of enzymes that are expressed from the genome, since we show that even large DNA constructs (at least $6 \mathrm{~kb}$ ) can be randomly inserted into the $B$. subtilis genome by the Mariner transposon. In light of the broad host-range of the Mariner transposon, such strategy is especially useful for production organisms for which no convenient genome recombination system is available. 


\section{METHODS}

\section{Bacterial strains and growth conditions}

For cloning purposes E. coli DH5 $\alpha$ was used. The GFP and $\beta$-galactosidase experiments were performed in B. subtilis strain W168 (lacA::tet aprE::lacl, cat). Cells were grown in Luria-Bertani (LB) medium with the addition of $10 \mu \mathrm{g} / \mathrm{ml}$ kanamycin for overnight cultures. No antibiotics were added when cells were assayed. Minimal medium was based on Spizizen's minimal medium and consists of 2 $\mathrm{g} / \mathrm{l}(\mathrm{NH} 4)_{2} \mathrm{SO}_{4}, 14 \mathrm{~g} / \mathrm{K} \mathrm{K} \mathrm{HPO}_{4}, 6 \mathrm{~g} / \mathrm{K} \mathrm{KH}_{2} \mathrm{PO}_{4}, 1 \mathrm{~g} / \mathrm{l}$ sodium citrate, $2 \mathrm{~g} / \mathrm{MgSO} \mathrm{M}_{4}, 5 \mathrm{~g} / \mathrm{l}$ glucose, $2 \mathrm{~g} / \mathrm{l}$

tryptophan, $0.2 \mathrm{~g} / \mathrm{l}$ casamino acids, and $2.2 \mathrm{~g} / \mathrm{l}$ ammonium ferric citrate. ${ }^{25}$ Pre-cultures were performed by growing cells from the overnight culture in fresh media until they reached exponential phase. Then all cultures were diluted to $\mathrm{OD}_{600} \sim 0.05$ and grown until the samples reached an $\mathrm{OD}_{600} \sim 0.5$ and 3.0.

\section{Plasmid and strain construction}

A unique cloning site was created in $\mathrm{pMarB}^{15}$ by linearizing the plasmid with the PCR primer pair oSS330/oSS331 (Supporting Information Table S1). The PCR product was digested with Munl and ligated, resulting in plasmid pSS121. The reporter cassette was assembled using splicing by overlap extension PCR..$^{26}$ gfp was amplified from pSG1729-gfp using oligo primer pair oSS346/oSS258, $\mathrm{P}_{\text {veg }}$ was amplified from chromosomal DNA of $B$. subtilis W168 with primer pair oSS259/oSS260, and lacZ was amplified from pMUTIN4 with primer pair oSS261/oSS262. The $\mathrm{P}_{\text {spac }}$ promoter was introduced by overhangs in primers oSS260 and oSS261. The three fragments were joined stepwise using oSS346 as the terminal gfp primer, and oSS347 as the terminal lacZ primer, which also introduced BamHI sites at both ends of the final construct. The components were first assembled into pUC19. The bidirectional transcriptional terminator ezrA/braB was PCR amplified from the chromosomal DNA of $B$. subtilis W168 using primer pair oSS344/oSS345 containing Sacl restriction sites, and subsequently cloned into the Sacl site of pUC19 resulting in pSS116. The BamHI site of pSS116 was used to introduce the $\mathrm{P}_{\text {veg- }}$ gfp/Pspac-lacZ fragment (pSS117). A bidirectional transcriptional terminator was incorporated into the Sphl site of pSS117 by amplifying the ywoG/ywoF terminator using primer pair oSS348/oSS349 (pSS118). Both terminators were identified using the WebGeSTer database. ${ }^{19}$ EcoRI and Hindlll sites 
were used to excise the reporter cassette from pSS118 and for cloning into Munl digested pSS121, after the insert and vector were blunt-end following a treatment with the Klenow fragment of DNA polymerase I. The resulting transposon vector was called pSS125 (Supporting Information Figure S6).

\section{Transposon selection}

The transposon procedure was based on that described by Lampe and Le Breton. ${ }^{14,15}$ B. subtilis W168 was transformed with pSS125 and transformants were selected on erythromycin containing plates at $30^{\circ} \mathrm{C}$. A few colonies were taken and cultured in LB medium for $3-5$ hours at $30^{\circ} \mathrm{C}$ and spread on nutrient agar plates with kanamycin at several dilutions from $10^{-3}$ to $10^{-5}$. The plates were incubated overnight at $50^{\circ} \mathrm{C}$, the non-permissive temperature for the plasmid, favoring the integration of the $\mathrm{P}_{\text {veg }}$ $g f p / P_{s p a c}-l a c Z$ fragment and the kanamycin-resistance cassette by the plasmid-encoded transposase. Undesired strains that still contained the plasmid were identified via the screening of plates containing erythromycin positive clones. Strains which were only resistant to kanamycin were used for further experiments. Transposon insertion efficiencies were determined by comparing the number of colonies with the desired kanamycin resistance, revealing a successful integration of the expression cassette, with the number of colonies having both kanamycin and erythromycin resistance, reflecting the presence of the plasmid (Supporting Information Table S2). Colonies were plated on nutrient agar plates containing $40 \mu \mathrm{g} / \mathrm{ml}$ of X-gal and $10 \mu \mathrm{M}$ IPTG to select clones by color.

To determine the transposon integration sites, arbitrary PCR was used as described by Knobloch. ${ }^{27}$ In short, PCR reactions were performed using GoTaq polymerase (Promega) and primer pairs Arb1/MarB1 or Arb1/MarB2. The thermocycler program began with an initial denaturation at $95^{\circ} \mathrm{C}$ for $5 \mathrm{~min}, 6$ cycles at $95^{\circ} \mathrm{C}$ for $1 \mathrm{~min}, 30^{\circ} \mathrm{C}$ for $1 \mathrm{~min}, 72^{\circ} \mathrm{C}$ for $1 \mathrm{~min}, 30$ cycles at $95^{\circ} \mathrm{C}$ for $30 \mathrm{sec}, 50^{\circ} \mathrm{C}$ for $30 \mathrm{sec}, 72^{\circ} \mathrm{C}$ for $1 \mathrm{~min}$ and a final extension at $72^{\circ} \mathrm{C}$ for $7 \mathrm{~min}$. In the second PCR step primer pairs Arb2/MarB1 or Arb2/MarB2 used $2 \mu$ of the first reaction as a template. For the $2^{\text {nd }}$ PCR the following programme was used: $95^{\circ} \mathrm{C}$ for $5 \mathrm{~min}, 6$ cycles at $95^{\circ} \mathrm{C}$ for $30 \mathrm{sec}, 50^{\circ} \mathrm{C}$ for $30 \mathrm{sec}, 72^{\circ} \mathrm{C}$ for $30 \mathrm{sec}, 30$ cycles at $95^{\circ} \mathrm{C}$ for $30 \mathrm{sec}, 58^{\circ} \mathrm{C}$ for $30 \mathrm{sec}, 72^{\circ} \mathrm{C}$ for $30 \mathrm{sec}$, and a final extension at $72^{\circ} \mathrm{C}$ for $7 \mathrm{~min}$. PCR products were sequenced using primer MarB1N or MarB2N. 


\section{$\beta$-galactosidase and GFP assays}

To measure $\beta$-galactosidase activities, cells were harvested and flash frozen using liquid nitrogen and stored at $-80^{\circ} \mathrm{C}$. $\beta$-galactosidase activity assays were performed according to the standard protocol of Miller, ${ }^{28}$ whereby cells were first lysed by adding $20 \mathrm{mg} / \mathrm{ml}$ lysozyme at room temperature for $30 \mathrm{~min}$.

To determine GFP levels, cells were washed in PBS after sampling. A sample of $0.3 \mu$ was applied to a GeneFrame (AbGene, Surrey, UK) containing $1.25 \%$ agarose in PBS, supplemented with $2 \mu \mathrm{g} / \mathrm{ml}$ of DAPI. For microscopic measurements, a Zeiss $200 \mathrm{M}$ microscope was used with the following excitation filters and exposure times: GFP (470/525) for 500 ms; DAPI (350/460) for 1000 ms. Microscopy images were analyzed using in-house software (NucTracer) that uses the DAPI stained nucleoid as identifier for the region of interest to measure GFP fluorescence in the cell. NucTracer is based on the ImageJ plugin ObjectJ that supports graphical vector objects identifying images on a transparent layer. 29,30

\section{DNA copy numbers analysis}

DNA copy number analysis was performed as described by Murray and Koh. ${ }^{20}$ In short, chromosomal DNA was isolated during exponential $\left(\mathrm{OD}_{600} \sim 0.5\right)$ and stationary phase $\left(\mathrm{OD}_{600} \sim 3.0\right)$. As a control for single copy number, DNA from $B$. subtilis spores was isolated. Regions of origin (oriC) and terminus (ter) of replication and the transposon locations were amplified using the primers listed in Supporting Information Table S2. qPCR was performed using $\mathrm{iQ}^{\mathrm{TM}}$ SYBR® green supermix (Bio-Rad) in a C1000 thermal cycler (CFX96 real-time system, Bio-Rad). A relative quantification analysis $\left(\Delta \Delta \mathrm{C}_{\mathrm{q}}\right)$ was performed by determining quantification cycles $\left(\mathrm{C}_{\mathrm{q}}\right)$ to calculate the ratios of transposon location compared to ter and by normalizing to the ori:ter ratio of chromosomal DNA of spores that contain one chromosome reflecting an equivalent ratio of 1 . Two loci were excluded from the analysis $\left(1^{\circ}\right.$ and $\left.241^{\circ}\right)$ due to primer inefficiencies during qPCR.

\section{SUPPORTING INFORMATION}

Table S1: Transposon insertion efficiency of the expression cassette comparing pSS125 to pMarB Table S2: Primers used in this study 
Figure S1: Growth rate measurement of transposons

Figure S2: Overview of the chromosomal transposon insertion sites

Figure S3: Effect of chromosomal location and transcription direction on gene expression

Figure S4: Transcriptional read-through measured by $\beta$-galactosidase assays in the absence of IPTG

Figure S5: Expression differences in stationary growth

Figure S6: Plasmid map of pSS125

\section{ACKNOWLEDGEMENTS}

C.S. and R.C. were supported by the European Commission funded Marie Curie Initial Training Network ATRIEM (project No. 317228). S.S. was supported by a BBSRC DTG PhD studentship. L.C.B was supported by the European Commission funded Marie Curie Innovative Training Network AMBER (project No. 317338), and L.W.H was supported by an NWO STW-Vici (12128) grant. 


\section{REFERENCES}

[1] Radeck, J., Kraft, K., Bartels, J., Cikovic, T., Durr, F., Emenegger, J., Kelterborn, S., Sauer, C., Fritz, G., Gebhard, S., et al. (2013) The Bacillus BioBrick Box: generation and evaluation of essential genetic building blocks for standardized work with Bacillus subtilis, Journal of biological engineering 7, 29.

[2] Niaudet, B., Janniere, L., and Ehrlich, S. D. (1985) Integration of linear, heterologous DNA molecules into the Bacillus subtilis chromosome: mechanism and use in induction of predictable rearrangements, Journal of bacteriology 163, 111-120.

[3] Young, M. (1983) The mechanism of insertion of a segment of heterologous DNA into the chromosome of Bacillus subtilis, Journal of general microbiology 129, 1497-1512.

[4] van Dijl, J. M., and Hecker, M. (2013) Bacillus subtilis: from soil bacterium to super-secreting cell factory, Microbial cell factories 12, 3.

[5] Sousa, C., de Lorenzo, V., and Cebolla, A. (1997) Modulation of gene expression through chromosomal positioning in Escherichia coli, Microbiology 143 ( Pt 6), 2071-2078.

[6] Couturier, E., and Rocha, E. P. (2006) Replication-associated gene dosage effects shape the genomes of fast-growing bacteria but only for transcription and translation genes, Molecular microbiology 59, 1506-1518.

[7] Kunst, F., and Ogasawara, N., and Moszer, I., and Albertini, A. M., and Alloni, G., and Azevedo, V., and Bertero, M. G., and Bessieres, P., and Bolotin, A., and Borchert, S., et al. (1997) The complete genome sequence of the gram-positive bacterium Bacillus subtilis, Nature 390, 249256.

[8] McLean, M. J., Wolfe, K. H., and Devine, K. M. (1998) Base composition skews, replication orientation, and gene orientation in 12 prokaryote genomes, J Mol Evol 47, 691-696.

[9] Zeigler, D. R., and Dean, D. H. (1990) Orientation of genes in the Bacillus subtilis chromosome, Genetics 125, 703-708.

[10] Mirkin, E. V., and Mirkin, S. M. (2005) Mechanisms of transcription-replication collisions in bacteria, Molecular and cellular biology 25, 888-895.

[11] Washburn, R. S., and Gottesman, M. E. (2011) Transcription termination maintains chromosome integrity, Proceedings of the National Academy of Sciences of the United States of America 108, 792-797.

[12] Block, D. H., Hussein, R., Liang, L. W., and Lim, H. N. (2012) Regulatory consequences of gene translocation in bacteria, Nucleic acids research 40, 8979-8992.

[13] Bryant, J. A., Sellars, L. E., Busby, S. J., and Lee, D. J. (2015) Chromosome position effects on gene expression in Escherichia coli K-12, Nucleic acids research 42, 11383-11392.

[14] Lampe, D. J., Churchill, M. E., and Robertson, H. M. (1996) A purified mariner transposase is sufficient to mediate transposition in vitro, The EMBO journal 15, 5470-5479.

[15] Le Breton, Y., Mohapatra, N. P., and Haldenwang, W. G. (2006) In vivo random mutagenesis of Bacillus subtilis by use of TnYLB-1, a mariner-based transposon, Applied and environmental microbiology 72, 327-333.

[16] Choi, K. H., and Kim, K. J. (2009) Applications of transposon-based gene delivery system in bacteria, Journal of microbiology and biotechnology 19, 217-228.

[17] Picardeau, M. (2010) Transposition of fly mariner elements into bacteria as a genetic tool for mutagenesis, Genetica 138, 551-558.

[18] Rubin, E. J., Akerley, B. J., Novik, V. N., Lampe, D. J., Husson, R. N., and Mekalanos, J. J. (1999) In vivo transposition of mariner-based elements in enteric bacteria and mycobacteria, Proceedings of the National Academy of Sciences of the United States of America 96, 16451650.

[19] Mitra, A., Kesarwani, A. K., Pal, D., and Nagaraja, V. (2011) WebGeSTer DB--a transcription terminator database, Nucleic acids research 39, D129-135.

[20] Murray, H., and Koh, A. (2014) Multiple Regulatory Systems Coordinate DNA Replication with Cell Growth in Bacillus subtilis, PLoS genetics 10, e1004731.

[21] Morimoto, T., Loh, P. C., Hirai, T., Asai, K., Kobayashi, K., Moriya, S., and Ogasawara, N. (2002) Six GTP-binding proteins of the Era/Obg family are essential for cell growth in Bacillus subtilis, Microbiology 148, 3539-3552. 
[22] Real, G., and Henriques, A. O. (2006) Localization of the Bacillus subtilis murB gene within the dcw cluster is important for growth and sporulation, Journal of bacteriology 188, 1721-1732.

[23] Chai, Y., Norman, T., Kolter, R., and Losick, R. (2011) Evidence that metabolism and chromosome copy number control mutually exclusive cell fates in Bacillus subtilis, The EMBO journal 30, $1402-1413$.

[24] Narula, J., Kuchina, A., Lee, D. Y., Fujita, M., Suel, G. M., and Igoshin, O. A. (2015) Chromosomal Arrangement of Phosphorelay Genes Couples Sporulation and DNA Replication, Cell 162, 328337.

[25] Spizizen, J. (1958) Transformation of Biochemically Deficient Strains of Bacillus Subtilis by Deoxyribonucleate, Proceedings of the National Academy of Sciences of the United States of America 44, 1072-1078.

[26] Horton, R. M. (1995) PCR-mediated recombination and mutagenesis. SOEing together tailor-made genes, Molecular biotechnology 3, 93-99.

[27] Knobloch, J. K., Nedelmann, M., Kiel, K., Bartscht, K., Horstkotte, M. A., Dobinsky, S., Rohde, H., and Mack, D. (2003) Establishment of an arbitrary PCR for rapid identification of Tn917 insertion sites in Staphylococcus epidermidis: characterization of biofilm-negative and nonmucoid mutants, Applied and environmental microbiology 69, 5812-5818.

[28] Miller, J. H. (1972) Assay of $\beta$-galactosidase, In Experiments in molecular genetics 3rd ed., pp 352-355, Cold Spring Harbor Laboratory Press, New York.

[29] Vischer, N. O. E., Huls, P. G., and Woldringh, C. L. (1994) Object-Image: An Interactive Image Analysis Program Using Structured Point Collection, Binary 6, 160-166.

[30] Syvertsson, S., Vischer, N. O., Gao, Y., and Hamoen, L. W. (2016) When Phase Contrast Fails: ChainTracer and NucTracer, Two ImageJ Methods for Semi-Automated Single Cell Analysis Using Membrane or DNA Staining, PloS one 11, e0151267. 


\section{FIGURE LEGENDS}

Figure 1. Schematic overview of the Mariner transposon containing the bidirectional reporter cassette. The housekeeping SigA-dependent $\mathrm{P}_{\text {veg }}$ promoter and the inducible $\mathrm{P}_{\text {spac }}$ promoter are fused to gfp and lacZ, respectively, and located between strong intrinsic transcription terminators $(T)$ to prevent readthrough from and into adjacent genes. The transposons are selected by kanamycin resistance $\left(\mathrm{kan}^{R}\right)$. The inverse terminal repeats (ITR) used by the transposase are indicated. The lacl gene coding for the repressor of the $\mathrm{P}_{\text {spac }}$ promoter is integrated at the genomic aprE locus (not indicated).

Figure 2. Chromosomal location of selected transposon mutants. Arrows indicate the orientation of the gfp marker and the location is given in degrees $\left(1^{\circ} \triangleq 11,708\right.$ base pairs). The origin of replication (oriC) and replication terminus (ter) are indicated. In $B$. subtilis the ter region is located approximately $178.7^{\circ}$ on the $B$. subtilis genome. DNA replication directions are indicated.

Figure 3. Effect of chromosomal location on gene expression. Cells were grown in LB medium at $37^{\circ} \mathrm{C}$ and samples were taken during exponential growth $\left(\mathrm{OD}_{600} \sim 0.5\right)$. (A) $\beta$-galactosidase activities (blue) and GFP fluorescence (red) are plotted relative to the chromosomal locations (degrees) of the transposons. Error bars indicate standard deviations of two technical replicates in case of $\beta$ galactosidase and at least 100 cells for GFP. The triangles indicate transcriptional direction of lacZ or gfp. Two outliers are marked by grey arrows. Goodness of fit for $\beta$-galactosidase with $R^{2}=0.86$ (excluding locus at $1^{\circ}$ ) and GFP with $R^{2}=0.70$. (B) Visual differences in GFP expression illustrated by fluorescence micrographs of four different transposons. Scale bar $5 \mu \mathrm{m}$. (C) DNA copy numbers of transposon locations determined by qPCR. Error bars indicate standard deviations of three biological replicates. Goodness of fit with $\mathrm{R}^{2}=0.78$.

Figure 4. Effect of gene orientation on gene expression. $\beta$-galactosidase activities (A) and GFP fluorescence intensities (B) from Figure 3 are plotted against the distance of the transposon insertion 
sites from the origin of replication (oriC). Triangles indicate the transcriptional direction of the reporter genes. Reporter genes that are transcribed in the same direction as DNA replication are shown in blue and genes that are transcribed against the DNA replication direction are shown in red. Error bars indicate the standard deviation of two technical replicates in case of $\beta$-galactosidase and at least 100 cells for GFP. Goodness of fit for $\beta$-galactosidase with $R^{2}=0.60$ (blue), $R^{2}=0.91$ (red) and for GFP with $\mathrm{R}^{2}=0.82$ (blue), $\mathrm{R}^{2}=0.66$ (red).

Figure 5. Influence of growth conditions on gene expression. The fold expression differences of $\beta$ galactosidase and GFP under different growth conditions were calculated by dividing the average expression levels of two loci close to the origin by that of two loci close to the terminus of replication. Cells were grown in LB medium (blue) and minimal medium (green) at $37^{\circ} \mathrm{C}$, and in LB medium at $30^{\circ} \mathrm{C}$ (red). Error bars indicate the standard deviation of three biological replicates.

Figure 6. Reporter gene expression in stationary growth. (A) Transposon strains were grown in LB at $37^{\circ} \mathrm{C}$ and lacZ expression was induced with $1 \mathrm{mM}$ IPTG at the start of growth $\left(\mathrm{t}_{0}\right)$ after which cells were harvested 3.5 hours later $\left(t_{1}\right)$, or at the beginning of the stationary phase $\left(t_{1}\right)$ after which cells were harvested 2 hours later $\left(\mathrm{t}_{2}\right)$. (B) $\beta$-galactosidase activities (blue) and GFP fluorescence (red) are plotted against chromosomal location (degrees) of the transposons when $1 \mathrm{mM}$ IPTG was added at the start $\left(\mathrm{t}_{0}\right)$ of growth. Error bars indicate the standard deviation of two technical replicates in case of $\beta$ galactosidase and at least 100 cells for GFP. Goodness of fit for $\beta$-galactosidase with $R^{2}=0.77$ (excluding locus at $1^{\circ}$ ) and GFP with $R^{2}=0.80$. (C) $\beta$-galactosidase activities when $1 \mathrm{mM}$ IPTG was added in the beginning of the stationary growth phase $\left(t_{1}\right)$. Average values with standard deviations of three independent biological replicates are shown. Direction of the triangles indicates transcriptional direction of lacZ or gfp. Goodness of fit for $\beta$-galactosidase with $R^{2}=0.34$. (D) DNA copy numbers of transposon locations determined by qPCR. Error bars indicate standard deviations of three biological replicates. Goodness of fit with $\mathrm{R}^{2}=0.42$. 
Figure 1

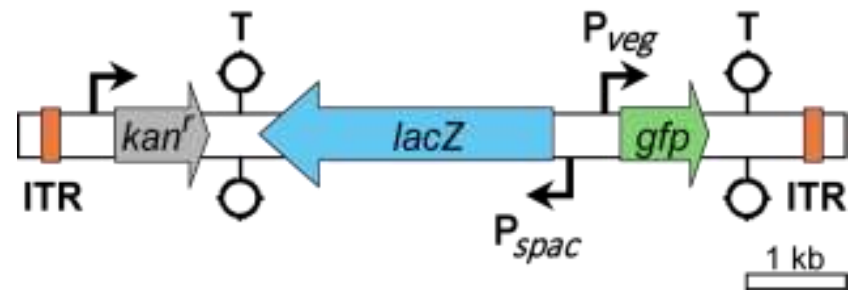


Figure 2

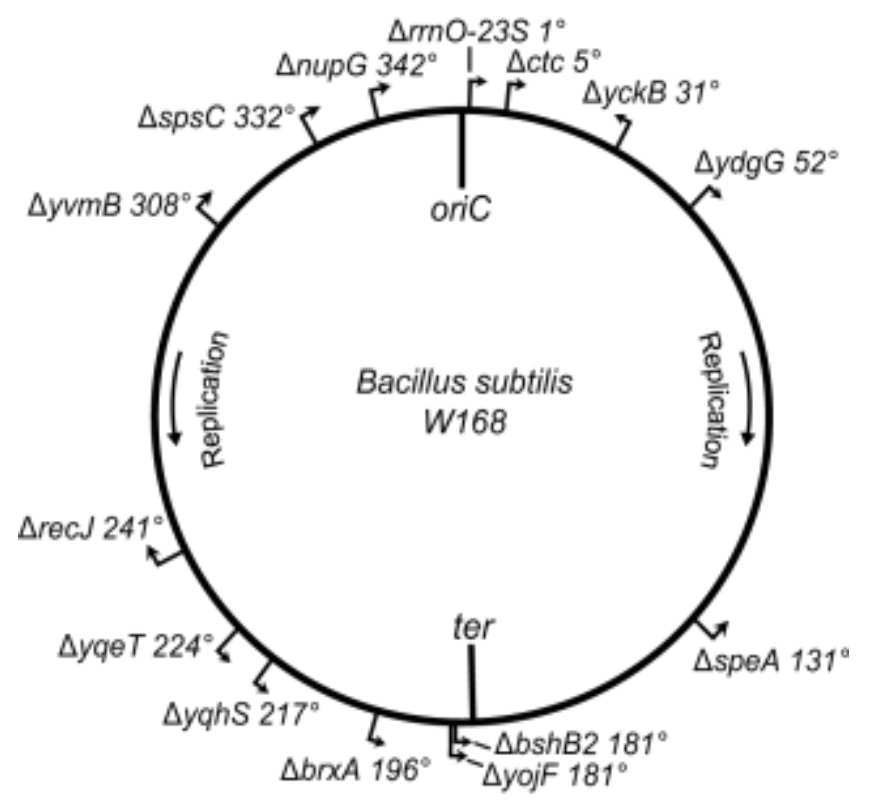


Figure 3

A

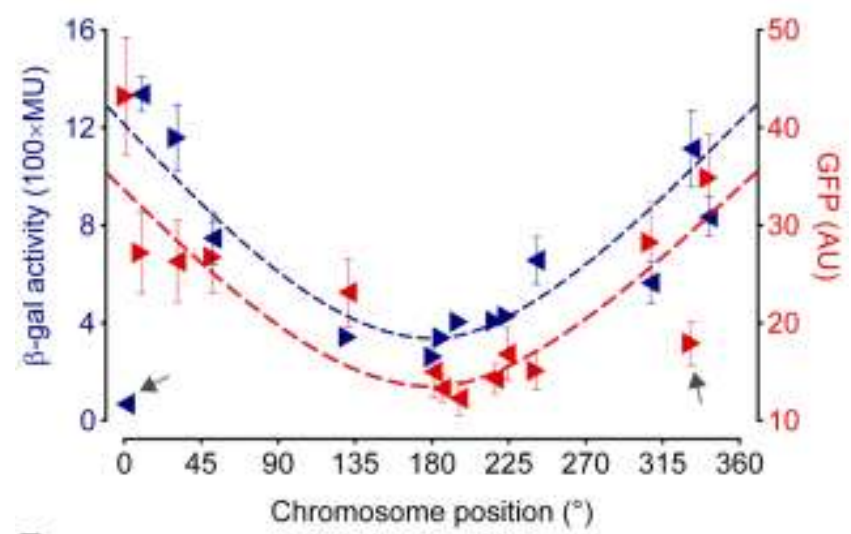

B

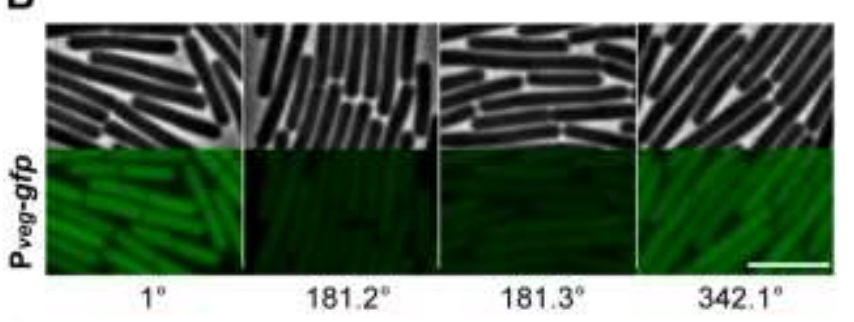

C

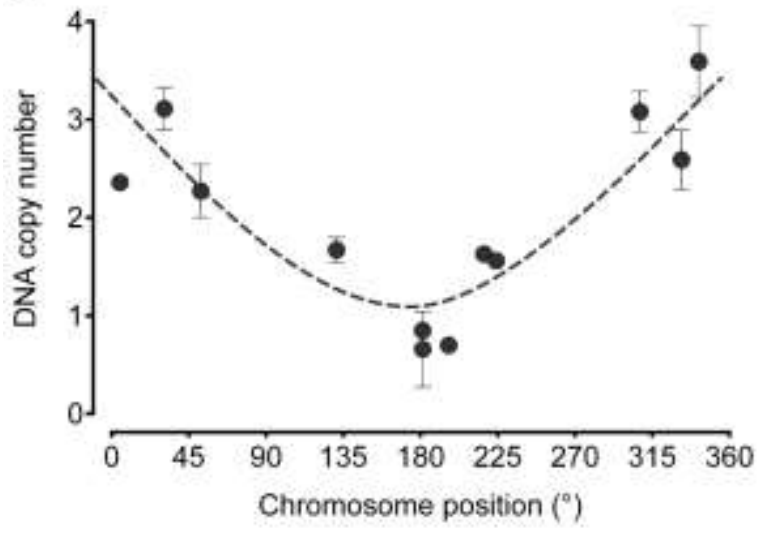


Figure 4

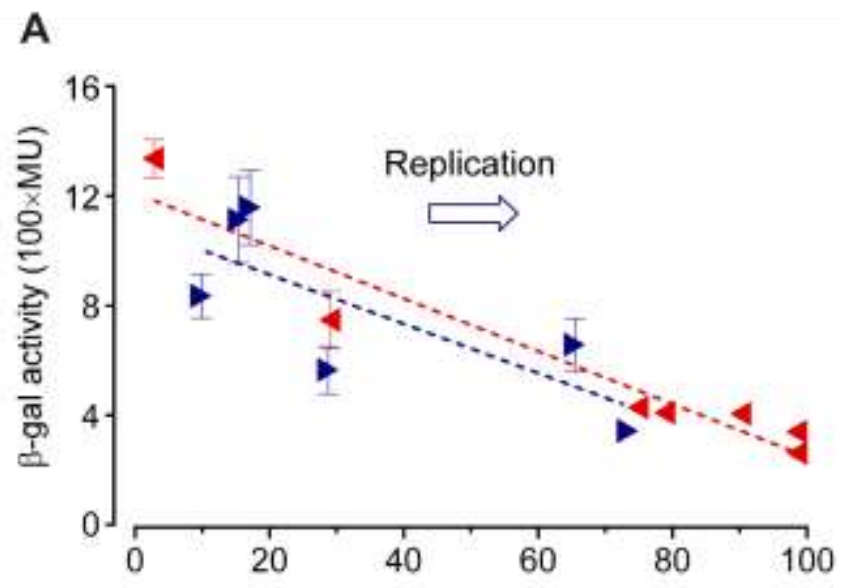

B

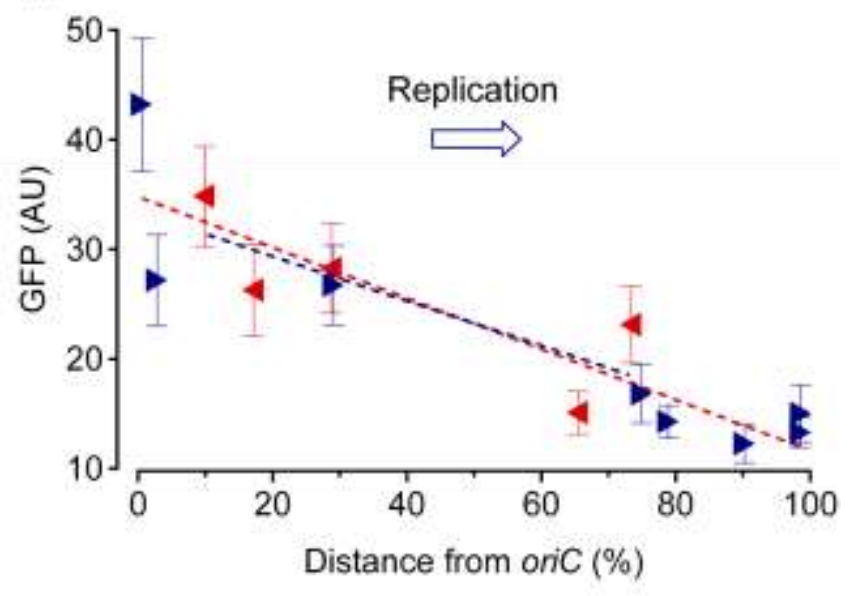


Figure 5

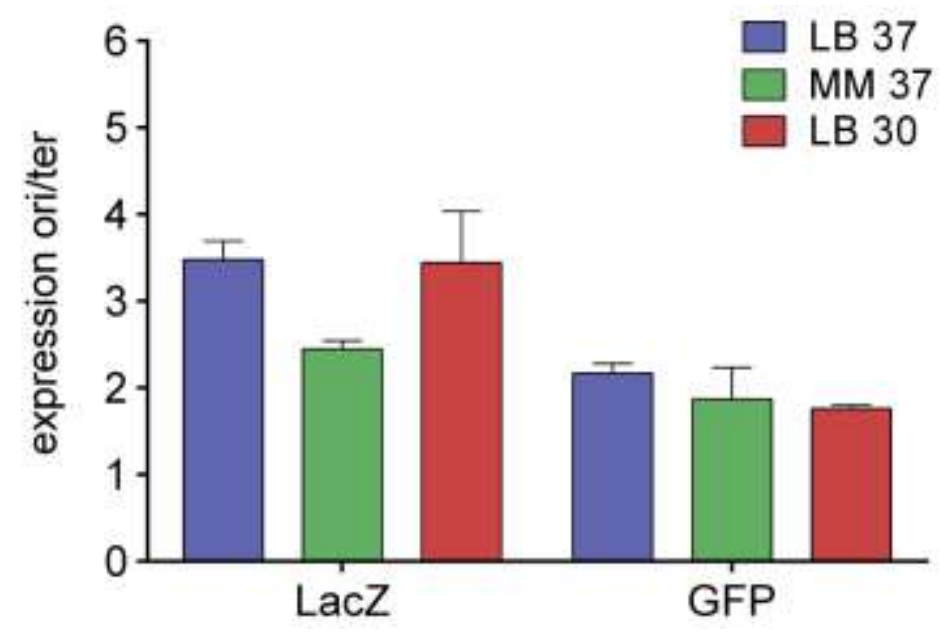


Figure 6
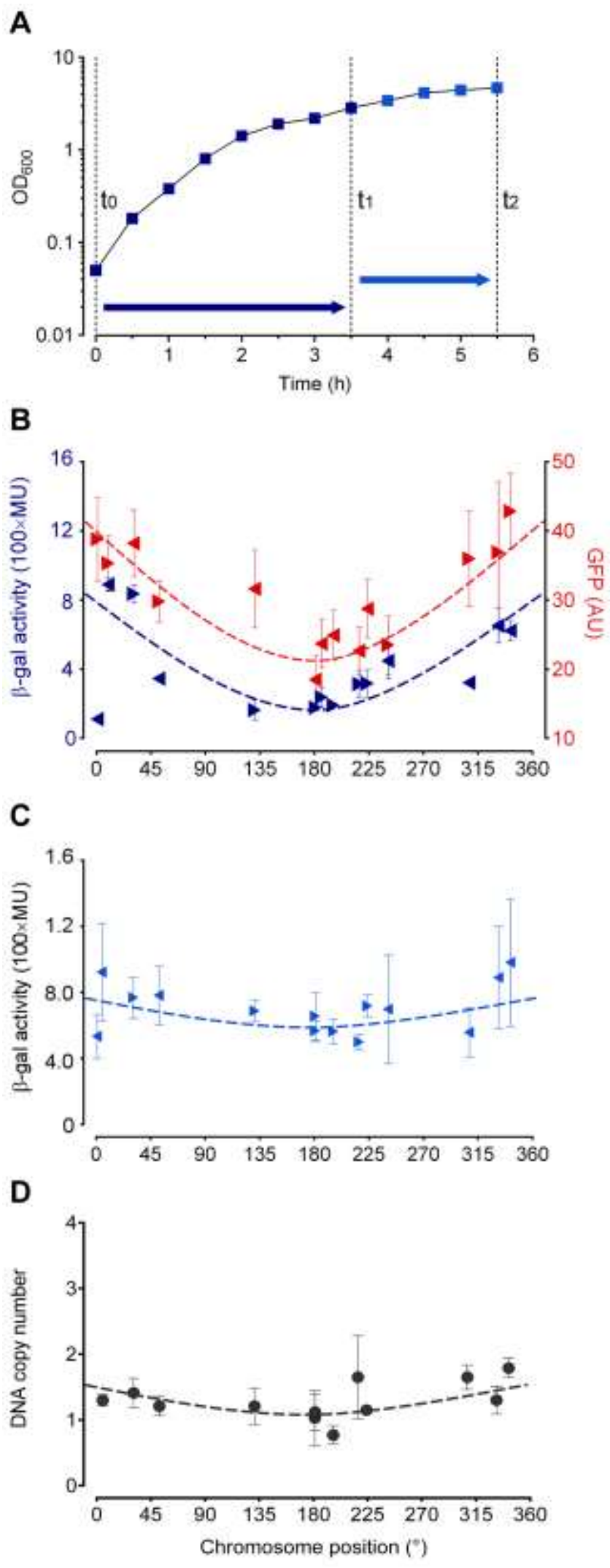